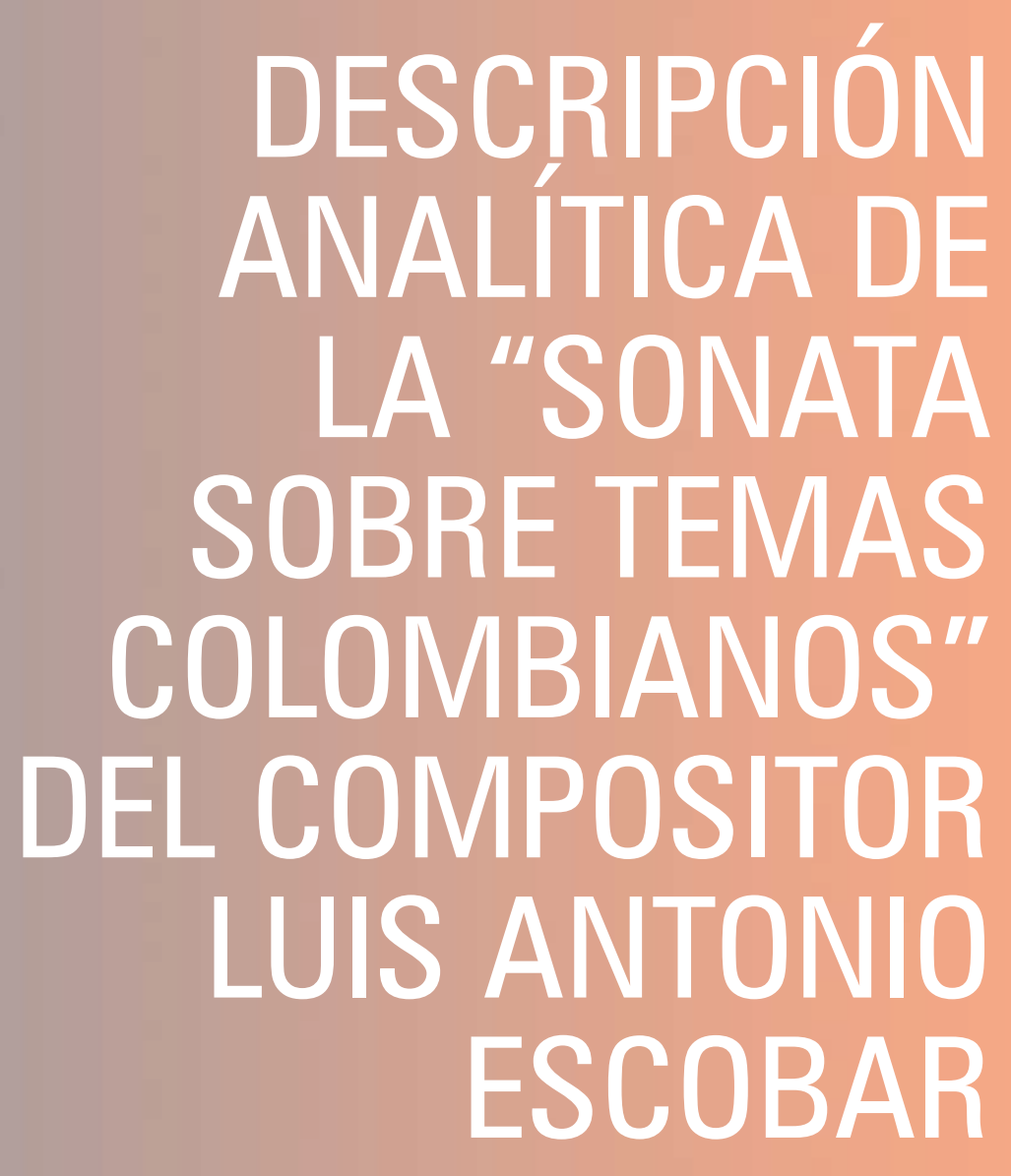

Luis Antonio Rojas Granada Magister en Música Universidad EAFIT. Énfasis Violín. Concertino asistente de la Orquesta Sinfónica EAFIT. Contacto: luisantoniorojas@yahoo.com DOI: 10.17230/ricercare.2014.1.6/

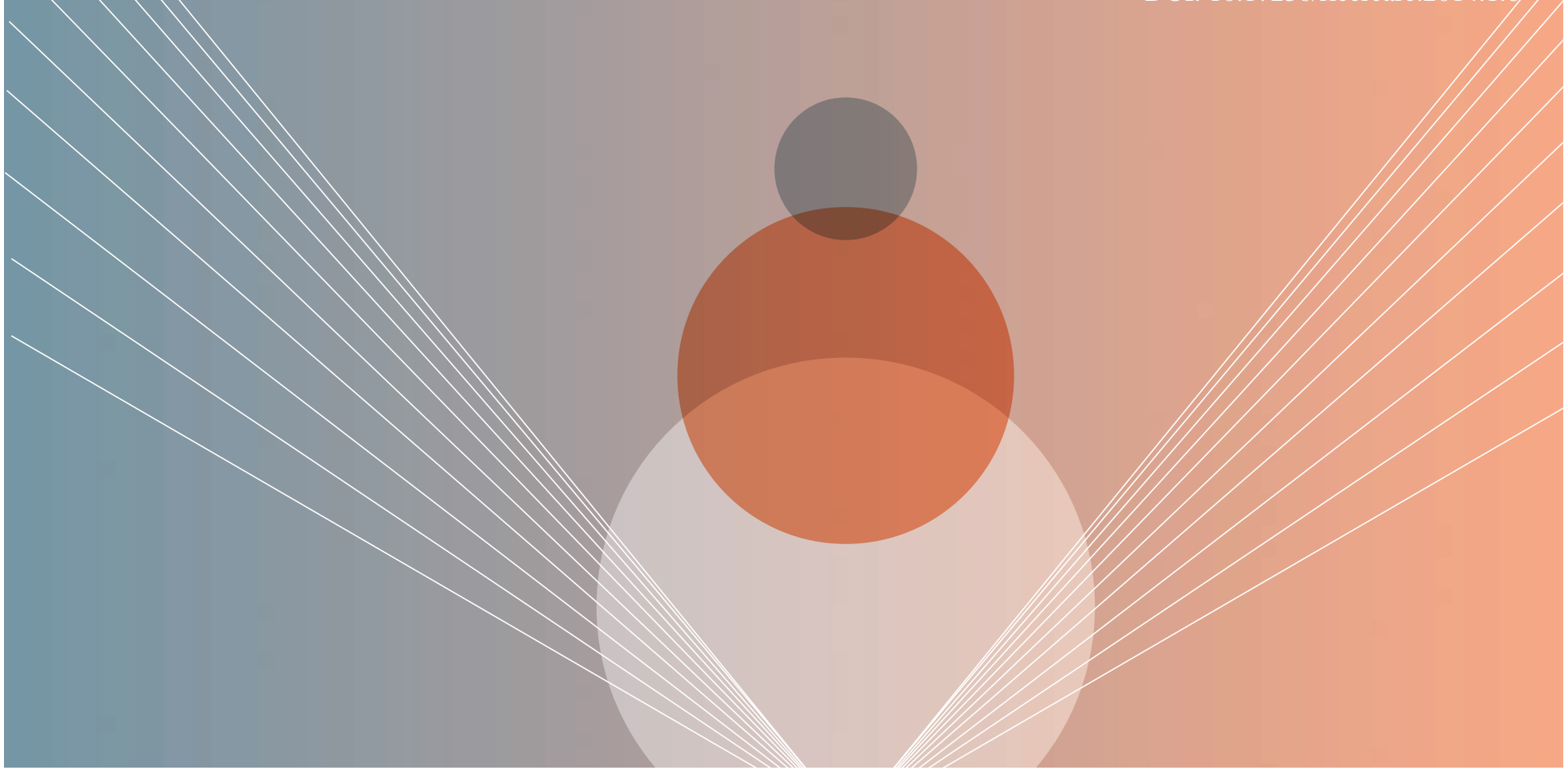


RESUMEN. El propósito de este trabajo es el rescate de la sonata "sobre temas colombianos" del compositor Luis Antonio Escobar. La partitura, compuesta en 1948 para ser presentada al concurso Música de Colombia Fabricato de ese año, reposa en la sala patrimonial del centro cultural Biblioteca Luis Echavarría Villegas de la Universidad EAFIT en Medellín- Colombia. El trabajo pretende determinar los elementos musicales de la obra y realzar su contenido artístico. A través de la descripción y del análisis de la partitura, cuya transcripción se toma aquí como fuente primaria, se identifican el lenguaje musical, las tendencias artísticas, estilísticas y su desarrollo creativo. Encriptadas en sus notas, se encuentran tanto las primigenias influencias nacionales del compositor, como las nuevas, adquiridas en ese entonces por su recién iniciado estudio superior de música en Estados Unidos. La obra pone en relieve algunos elementos musicales inherentes al compositor.

PALABRAS CLAVES: Sonata, Luis Antonio Escobar, Concurso Música de Colombia Fabricato.

\section{ANALITICAL DESCRIPTION OF THE “SONATA ON COLOMBIAN THEMES” BY LUIS ANTONIO ESCOBAR}

ABSTRACT. The purpose of this work is the rescue of the sonata "on Colombian themes" of the composer Luis Antonio Escobar. The score, composed in 1948 intended to be presented to the music of Colombia Fabricato contest that year, can be found in the Heritage Hall of the cultural center library Luis Echavarria Villegas of the Universidad EAFIT in Medellín - Colombia.The work aims to determine the musical elements of the work and enhance its artistic content. Through description and analysis of the score, whose transcription is taken here as a primary source, the musical language, artistic, stylistic trends and its creative development are identified. Encrypted in its notes, are both primordial national composer influences, and new, acquired at that time by its newly started upper study of music in the United States. The work puts in relief some musical elements inherent in the composer.

KEYWORDS: Sonata, Luis Antonio Escobar, Contest Música de Colombia Fabricato 


\section{INTRODUCCIÓN}

En el año de 1948, la empresa textil FABRICATO de Medellín decidió realizar un concurso de música colombiana como celebración de su aniversario. Este concurso, con fines filantrópicos y propagandísticos, convocó, como lo afirma Gil (2006), a gran cantidad de compositores que vieron en él una vitrina dónde mostrar su música. Uno de ellos fue Luis Antonio Escobar, quien envió la sonata con el seudónimo "ESSE". Como queda registrado por Sierra (1948), la obra fue merecedora de una mención de honor.

La excusa perfecta para hablar del compositor es su obra; por lo mismo, cuenta este escrito con una recopilación biográfica de Escobar, que agrupa variedad de títulos. Se presenta también un capítulo que habla del catálogo de sus obras. Tuviéronse en cuenta textos extranjeros que, aunque de poca profundidad, dan muestra de los alcances internacionales del músico.

El capítulo concerniente al Concurso Música de Colombia Fabricato pretende ubicar al lector en el contexto musical de la época, de gran importancia para el desarrollo del nacionalismo musical en el país. Se consultaron los escritos de aquel tiempo y las nuevas investigaciones que sobre éste se han elaborado.

El análisis de la Sonata de estudio está acompañado de una propuesta interpretativa desde el punto de vista violinístico. Se anexa la primera edición de la partitura que contiene algunas correcciones, como se explica posteriormente, y se incluye un capítulo con una propuesta interpretativa sustentada con una grabación, que pretende guiar al violinista intérprete dentro del concepto musical del autor.

\section{BIOGRAFÍA}

El compositor colombiano Luis Antonio Escobar nace en el año de 1925 en Villapinzón, Cundinamarca y muere en el año 1993 en Miami, Estados Unidos. Inicia sus estudios musicales de manera informal en su pueblo natal. Posteriormente, ingresa al Conservatorio Nacional de Música de la Universidad Nacional de Colombia en Bogotá. No requiere de mucho tiempo en esta institución para sobre- salir y hacerse acreedor a una beca que lo llevaría a Baltimore, Estados Unidos, a estudiar composición. Se traslada luego a Alemania para continuar sus estudios ${ }^{1}$.

Muy cercana al autor es la semblanza que hace su esposa Amparo Ángel, publicada en el libro Ecos, Contextos y Desconciertos del Doctor Fernando Gil, donde relata que:

Luis Antonio fue un enamorado de la música Colombiana. Desde su niñez tuvo toda la influencia del folclor de su pueblito que era Villapinzón... también los instrumentos musicales folclóricos como el requinto, la carraca, el tiple, la bandola, todos estos instrumentos y los aires colombianos influyeron muchísimo en su creación musical, que tiene un toque muy acentuado de música nacionalista colombiana del altiplano cundiboyacense (Gil, 2003).

Lo anteriormente descrito confirma la relación que existe entre el contexto sociohistórico y la música de Escobar.

Como se decía, Luis Antonio depuró su arte compositivo en Estados Unidos, con Nicolás Nabokov en 1947, y en Alemania, con Boris Blacher entre 1951 y $1953^{2}$. Sobre este último maestro, Amparo Ángel, en entrevista documentada en el texto de Gil, nos aclara las intenciones estilísticas de su música: "Este compositor [refiriéndose a Blacher] tiene una línea melódica y armónica muy moderna que influyó muchísimo en las primeras obras" (Gil, 2006). Ángel (2001) señala tres etapas en su vida profesional, posteriores a su estudio en el exterior. Estas etapas no se definen por su estilo compositivo, o por la evolución de su música, sino por su labor y producción musical.

La reseña general sobre la vida y obra del maestro se encuentra en The New Groves Dictionary of Music and Musicians (Sadie, 1980). También apareció un aparte en el Diccionario de la Música Española y Latinoamericana (López Calo, Casares Rodicio y Fernandez de la Cuesta, 1999), que detalla algunos aspectos sobre su obra y otro en la página del Banco de la República (Atehortúa Almanya, 1980). La biografía más completa es la realizada por Amparo Ángel, publicada también en la página del Banco de la República. (Angel, 2001)

La información sobre ambos compositores se puede encontrar en SADIE, Stanley. The new grove dictionary of music and musicians. Londres: Macmillan. 1980, Vol. 2, p. 766, Vol. 13, p 10 


\section{Primera etapa profesional 1954-1957}

Cuando regresa a Colombia, realiza varios conciertos con la orquesta Sinfónica, dando a conocer su trabajo, recibido por el público y por la crítica favorablemente. Ya reconocido como compositor, las orquestas interpretaron permanentemente sus obras. Había logrado imprimir a su música un estilo nacionalista depurado, producto del recuerdo de las melodías y ritmos escuchados en su niñez y del cúmulo de conocimientos adquiridos durante sus estudios en Estados Unidos y Europa (Ángel, 2001). En este período, se dedica a la pedagogía y a la participación en programas musicales de radio y televisión.

\section{Segunda etapa 1957-1975}

Se le otorga la beca Guggenheim, lo que le da la oportunidad de viajar por segunda vez a los Estados Unidos. De regreso, se concentra en la composición de obras. De esta época, datan las Cánticas Colombianas para coro. Ocupó también, en diversas ocasiones, cargos administrativos y diplomáticos.

\section{Tercera etapa 1976-1993}

Fue ésta una etapa creativa muy intensa. Compone en gran cantidad. Viaja por varios países como conferencista invitado. Recibe condecoraciones del gobierno Nacional por su labor en torno a la música. "Su obra, reconocida a nivel (sic) mundial, se interpreta en los países de América y Europa. Es una música que sintetiza el sentimiento de un pueblo latinoamericano, Colombia, y de manera exquisita da a conocer el sentir y el modo de ser de sus gentes" (Ángel, 2001).

Es importante recordar que este trabajo se concentra en la primera sonata de Escobar, del año 1948, marcada dentro de una tendencia nacionalista, en una dirección estética que inspira a los compositores de su tiempo ${ }^{3}$.

\section{CONCURSO MÚSICA DE COLOMBIA, PATROCINADO POR}

Como lo deja claro el siguiente comentario extraído de Temas con Variaciones (Gil, 2006)

\section{FABRICATO, 1948-1951}

El concurso fue el gran incentivo para la realización de la sonata que nos compete. Está claramente relacionado en una investigación de la Universidad EAFIT que, en dos publicaciones de Gil: Temas con Variaciones (Op. Cit.) y Ecos, Contextos y Desconciertos (Op. Cit.), describen su dinámica. El último título se refiere al proyecto de Investigación de la Universidad EAFIT - 2003, dirigido por el Dr. Fernando Gil Araque, donde se explica con detalle todo lo referente al concurso.

Del primer título, se pueden seleccionar algunos apartes que resaltan el aporte dado al desarrollo musical de la época:

Los concursos musicales han jugado un papel fundamental en el impulso de la composición musical colombiana, como promotores y validadores de nuevos formatos, estilos y estéticas musicales. Ellos han facilitado la renovación del repertorio musical, pero en algunos casos también se han aferrado a formatos tradicionales, en los que lo novedoso a veces se ve como una afrenta a la música.

Fueron vitales para la renovación de la música en Colombia en las décadas de los 30 y 40, los concursos Ezequiel Bernal en Bogotá y los concursos Indulana Rosellón (1941-1943) y Música de Colombia (1948 y 1951) patrocinado por Fabricato en Medellín (Gil, 2006).

Décadas después del conflicto entre Uribe Holguín y Murillo, (Bermudez, 1999) y cuando iba madurando un despertar de la conciencia musical nacional, el concurso, como lo reconoce Gil (2003), da su máximo aporte al "promover la composición musical en el país, en el campo académico y tradicional".

El Concurso Música de Colombia 1948-1951 renovó la composición al promover nuevos lenguajes en el campo sinfónico, la música de cámara y la música tradicional. Infortunadamente, no se ha valorado la importancia y los méritos que tuvo este certamen en la transformación del ejercicio de la música del país.

Mostró la realidad y el estado de la composición de la 
música sinfónica, de cámara y tradicional; marcó los anhelos de renovación y modernización de la música andina colombiana, tanto para sus organizadores, como para un grupo importante de compositores y se constituyó como la última fase del proyecto romántico en la música a medidos del s XX. Igualmente, promovió la participación de nuevos compositores y proyectó sus obras en diferentes lenguajes (Gil, 2003).

\section{CATÁLOGO DE OBRAS}

Un punto para aclarar con respecto a la obra de Escobar es el catálogo. Existen divergencias en relación con la Sonata que se estudia en este trabajo: la Sonata Número 1 Sobre Temas Colombianos y la Sonata Número 3 que, por haber sido también destinada al concurso, presenta confusión en cuanto a sus respectivas identidades individuales. Como se verá a continuación, algunos catálogos las incluyen, otros nó y, en algunos de ellos, los años no coinciden.

En el catálogo donado a la Universidad EAFIT por Juan Carlos Arango Montoya (1982), no figuran las composiciones enviadas al concurso que patrocinó FABRICATO. Es probable que esa omisión tenga su origen en el hecho de que las obras enviadas a dicho concurso debían marcarse con seudónimo y nó con el nombre del compositor. Esto impedía identificar claramente al autor, como ocurrió repetidas veces con varias obras, según se explica en Ecos, Con-textos y Des-conciertos: a la hora de relacionar obra con autor no se correspondían (Gil, 2003). Se debe cotejar el anterior catálogo con el realizado por Barreiro (2011), donde sí se incluyen ambas sonatas pero con distintos nombres. La primera de ellas, bajo el título de Sonatina 1 (1947), de la que se dice que "ganó el segundo premio en el concurso Coltejer" (Barreiro, 2011) y la segunda, la Sonatina de 1948, para violín y piano.

Aquí existe también una falsa correspondencia si se compara el anterior catálogo con el acta del concurso Fabricato, donde se registra en la edición de 1948 que: "La Sonata sobre temas Colombianos con seudónimo ESSE ganó mención de honor" y nunca "premio en Coltejer" (Sierra, 1948).

El concurso del año 1949 registra otra Sonata, ahora con seudónimo "Pandero". Hacemos referencia aquí a la So- nata 3 o Sonatina de 1948. Obviamente los trabajos son los mismos pero el año no corresponde. Barreiro, seguramente, tuvo en cuenta el año de composición de las obras mientras que, por otro lado, el concurso consideró el año de la premiación del evento.

Gil (2003) señala que la sonata para piano con seudónimo "navegante" y la sonata con seudónimo "pandero" recibieron mención. En el catálogo de referencia de las obras participantes del concurso FABRICATO del año 1949, así como en el acta del jurado, no se anota dicha mención.

Como conclusión, hace falta un catálogo completo del autor donde no existan divergencias y que contenga las fechas de composición y de edición manuscrita de las obras así como sus características principales ${ }^{4}$. Este esperado catálogo próximamente será terminado por Amparo Ángel aunque, según el mismo, la sonata aparecerá catalogada como sonatina, tal como la nombrara Barreiro.

\section{ANÁLISIS}

Un punto de partida interesante para acometer el análisis de la sonata es el comentario incluido en el acta del jurado calificador del concurso, registrado en la Revista Gloria, que dice:

...fue presentada en 1948 bajo el seudónimo de ESSE esta composición (que) es una obra de estudiante, pero en ella muestra su lenguaje y los recursos armónicos y melódicos que va a utilizar en sus obras posteriores. La obra consta de tres movimientos: Alegre, Tema y Variaciones, Alegre, en este último movimiento utiliza el aire de torbellino. La obra fue dedicada al compositor cartagenero Juan de Sanctio, quien era compañero de estudio en Baltimore (Sierra, 1948).

También se dice que la pieza es una: “obra moderna con momentos de gran inspiración y de excelente construcción" (Sierra, 1948).

\footnotetext{
$4 \quad$ Otro catálogo disponible en línea es el que aparece en la página del Banco de la República: BANCO DE LA REPUBLICA. Catálogo de obras. Obras para orquesta. [En Línea]. Bogotá: Biblioteca Luis Ángel Arango. (Citada: 7 de septiembre de 2012) http://www.banrepcultural. org/node/66131
} 
Sobre la estética y el lenguaje, Duque aclara que: "Para Luis Antonio Escobar el neoclasicismo es una opción para continuar con la vertiente nacionalista, repitiendo algunas temáticas, pero superándolas con el uso de la polifonía" (Duque, 1993).

\section{Primer movimiento}

La polimetría 3/4 - 6/8 es reflejada claramente en los primeros compases y se vuelve una constante, determinando un aire de bambuco. La sección en La no se reconoce en modo menor hasta seis compases después, con la entrada del grado VI en el tempo lento; existe una expectativa tonal. El movimiento presenta falsas relaciones, acordes incompletos, mixturas y sonoridades derivadas del Romanticismo tardío y de algunos nacionalismos interseculares, con acordes pluscuamtriádicos, novenas, sextas y undécimas comunes en ese lenguaje. Tiene forma bipartita con coda al final.

En el siguiente cuadro se exhibe la forma de este movimiento

Tabla 1. Esquema formal primer movimiento

\begin{tabular}{|l|l|l|l|l|}
\hline \multicolumn{1}{|c|}{ Tonalidad } & \multicolumn{1}{c|}{ Estructura } & \multicolumn{1}{c|}{ Tempos } & Motivos/Temas & Compases \\
\hline Mi bemol & S12 & Alegre & A & $1-10$ \\
\hline La menor & S12 & Alegre & B & $11-17$ \\
\hline La menor Mi bemol & S12 & Lento & B & $18-22$ \\
\hline Mi bemol & S23 & Alegre & Desarrollo & $22-34$ \\
\hline Sol menor & S23 & Alegre & Desarrollo & $35-53$ \\
\hline Fa & S23 & Alegre & B' & $53-64$ \\
\hline Mi bemol & Coda & Calmado & Coda & $65-74$ \\
\hline
\end{tabular}

Come se dijo anteriormente, el movimiento es una canción binaria de forma libre, con armonía no funcional.

La primera frase $\mathrm{F}_{1}$ es binaria $\left(\mathrm{F}_{1}^{2}\right)$ llega hasta el compás quinto sobre el primer tiempo. La segunda frase $\mathrm{F}_{2}$ es ternaria $\left(\mathrm{F}_{2}{ }^{3}\right)$ y llega al calderón sobre el acorde alemán, que determina el primer periodo binario $\mathrm{P}_{1}{ }^{2}$. La tercera frase es ternaria $\mathrm{F}_{3}{ }^{3}$, abarca los compases once al diecisiete. La cuarta frase está en tempo lento y es binaria $\mathrm{F}_{4}{ }^{2}$. Ambas forman el segundo periodo binario $\mathrm{P}_{2}^{2}$. Aquí concluye la primera sección, en el compás veintidós con la barra de repetición, $\mathrm{S}_{1}^{2}$.

La segunda sección se presenta como un desarrollo, que usa, en muchas de sus frases, cabezas de motivos. Cuenta con tres períodos y llega hasta la barra de repetición. La quinta frase es binaria $\mathrm{F}_{5}{ }_{5}^{2}$, entre los compases veintidós y veintiséis. La frase siguiente y las subsiguientes son también binarias: $\mathrm{F}_{6}{ }_{6}, \mathrm{~F}_{7}{ }^{2}$. La frase ocho $\mathrm{F}_{8}{ }^{3}$ es ternaria $\mathrm{y}$, a pesar de ser corta, usa varias cabezas de motivo. Hasta aquí el tercer periodo de desarrollo $\mathrm{P}_{3}{ }^{2}$. La coda, de diez compases, recuerda el motivo de $\mathrm{F}_{3}$ y está construida como imitación que va del violín al piano. Termina el movimiento con un calderón sobre quinto grado sin la tercera del acorde. 
Este movimiento contiene un lenguaje tonal libre. Recuerda el durchkomponiert ${ }^{5}$, que es precisamente fruto de la influencia de su maestro Nabokov. Es probable que el uso de esta técnica, que implica un constante flujo de ideas sin secciones ni identificaciones temáticas separables, fuese para Escobar la manera más adecuada para plasmar el desorden de las romerías que tanto lo influenciaron. El contraste y cambio de carácter es lo más importante de este movimiento. Los motivos a y b siempre se encuentran en diálogo en el desarrollo, no necesariamente sobre la estructura de pregunta respuesta, pero sí manteniendo un diálogo intenso, a juzgar por el carácter del motivo b, salpicado de trinos, armónicos, forte en dinámica, apasionado en intención sonora. El tempo Lento parece bajar el tono a la confrontación, que no llega a conclusión satisfactoria en su final, si consideramos el último acorde: $\mathrm{V}$ grado incompleto, sin tercera.

\section{Segundo movimiento}

Aquí la composición presenta gran cantidad de acordes incompletos, donde falta por lo general la tercera. Esta ausencia de la nota que define el modo, favorece la percepción de acordes compuestos por cuartas, es decir acordes cuartales o pandiatonismo, aunque sólo en sitios determinados.

De nuevo, se encuentran falsas relaciones. Existen acordes que se complementan entre sí; al estar cada uno incompleto, la armonía se llena entre ambos por efecto de recordar una sonoridad anterior, es decir, que usan dos sonoridades. El siguiente cuadro describe este movimiento:

Tabla 2. Esquema formal segundo movimiento

\begin{tabular}{|l|l|l|l|l|}
\hline \multicolumn{1}{|c|}{ TONALIDAD } & $\begin{array}{c}\text { ESTRUCTURA } \\
\text { variaciones }\end{array}$ & \multicolumn{1}{|c|}{ TEMPO } & MOTIVOS/TEMAS & \multicolumn{1}{c|}{ COMPÁS } \\
\hline Re bemol & Tema & Lento & A/B & $1-15$ \\
\hline Modulante & Variación I & Más Adagio & A/B & $16-29$ \\
\hline Re bemol & Variación II & Meditativo & C & $30-35$ \\
\hline Re bemol & Variación III & Meditativo/Lento & C & $36-41$ \\
\hline Re bemol & Variación IV & Lento & B & $42-50$ \\
\hline Do & Variación V & Lento/Coda & & $51-59$ \\
\hline
\end{tabular}

Este movimiento es un tema con Variaciones; el primer tema a es expuesto por el violín en la primera frase binaria $\mathrm{F}_{1}{ }^{2}$ en tonalidad de Re bemol. Para la segunda frase, el protagonista es el piano, que repite el tema. Una frase de cierre formada a partir del inciso b, concluye el periodo $\mathrm{P}_{1}{ }^{3}$. Hasta aquí la exposición del tema. La primera variación es en su forma igual al

5 Durchkomponiert (alem.), término que se usa para una obra, especialmente una canción, compuesta en forma continua, que no se repite en las sucesivas estrofas, al contrario de ESTRÓFICA. (Término que también a veces se utiliza para significar "totalmente elaborado" "realmente compuesto", etc., como diferente de lo que parece avanzar simplemente por fragmentos”). JACOBS, Arthur. Diccionario de la Música. Buenos Aires: Editorial Losada, 1995 
tema, pero con algunas notas añadidas en el acompañamiento del piano. Esta primera variación es formada por las frases $\mathrm{F}_{4}^{2} \mathrm{y} \mathrm{F}_{5}^{2}$ y forman en conjunto el período $\mathrm{P}_{2}^{2}$. La segunda variación cambia de métrica, ahora cuatro cuartos. Contiene dos frases $\mathrm{F}_{6}{ }^{3} \mathrm{y} \mathrm{F}_{7}{ }^{2} \mathrm{y}$ ambas forman el período $\mathrm{P}_{3}{ }^{2}$. Siguen ahora dos variaciones en tempo lento; una, con gran subdivisión de seisillos y otra en 3/4, que es la métrica inicial del movimiento; en este caso, ambas variaciones forman un período, por considerar que la segunda de ellas actúa como la frase de cierre de la exposición inicial del tema, al principio del movimiento.

Coda. Al final aparece un cuarto período $\mathrm{P}_{4}$ con un cambio de tono drástico que nos aleja del siempre escuchado Re bemol y nos brinda un Do mayor algo más cristalino y transparente por su acompañamiento sencillo de negras y corcheas. Temáticamente, la coda expone un nuevo material.

Es un movimiento reflexivo y muy íntimo. Una idea musical que cambia a lo largo de las variaciones pero que, en su esencia, sigue siendo la misma. Es una búsqueda interna a través del movimiento, que no halla respuesta en ningún momento. Sólo la quinta variación parece mostrar un nuevo aire, una ilusión. Pero esta búsqueda queda insatisfecha nuevamente hacia el final, por el acorde de segundo grado que no resuelve en fórmula cadencial.

\section{Tercer movimiento}

En aire de torbellino, este movimiento usa, en algunas secciones, un ostinato armónico con leves variaciones hacia el final de la frase.

Éste es el cuadro para el movimiento:

Tabla 3. Esquema formal tercer movimiento

\begin{tabular}{|l|l|l|c|l|}
\hline \multicolumn{1}{|c|}{ TONALIDAD } & ESTRUCTURA & \multicolumn{1}{c|}{ TEMPO } & MOTIVOS/TEMAS & \multicolumn{1}{c|}{ COMPÁS } \\
\hline Sol & S13 & Alegre & A/B & $1-37$ \\
\hline Si menor & S22 & Alegre & Desarrollo & $38-61$ \\
\hline Sol & Coda & Lento & A. Coda & $62-67$ \\
\hline
\end{tabular}

La primera frase $\mathrm{F}_{1}{ }^{2}$ incluye el motivo clásico del torbellino, que estará presente a lo largo del movimiento como un ostinato. La sección $\mathrm{S}_{1}$ consta de tres Períodos: $\mathrm{P}_{1}^{2}$ compases uno al doce, $\mathrm{P}_{2}{ }^{3}$ compases trece al veintiséis, y el $\mathrm{P}_{3}{ }^{3}$ compases veintisiete a treinta y siete. En esta sección prevalece el motivo del ostinato y el motivo de la frase segunda $\mathrm{F}_{2}{ }^{2}$. La segunda sección $\mathrm{S}_{2}$ muestra un desarrollo de los primeros motivos y giros armónicos en tonalidades distintas. La coda, de seis compases y por tanto de extensión frase, está construida sobre el ostinato característico del torbellino.

El torbellino, típico de la región de Boyacá y Santander, tiende a ser de impresión improvisatoria y es una guabina instrumental. Otro aire folclórico presente en el movimiento es el bambuco, que está incluido en una de sus formas métricas, en este caso de 3/4. No olvidar que, a veces, el bambuco se escribe también en 6/8. Vale aquí aclarar que la métrica de $3 / 4$ es más propia de la guabina, y la de 6/8 más predominante del bambuco. 
De carácter alegre y jocoso, contrasta con el movimiento anterior por su tonalidad y dinamismo musical. Desde un principio, el autor nos ubica en un terreno musical conocido al usar un aire folclórico nacional popular como es la Guabina. De esta manera, parecen despejarse todas las dudas acumuladas a lo largo de la obra; dudas incubadas en el primer movimiento y desarrolladas en el segundo. Esto, a pesar de que un juego armónico entre re y sol enturbie un poco la claridad tonal (no la calidad compositiva) de la respuesta.

En la sección de desarrollo, nuevamente el uso del durchkomponiert está presente, emparentando este movimiento con el primero. Otro elemento que sirve para dar unidad a la obra es el tempo Lento antes de la coda final, que se asemeja a los tempi lentos del primer movimiento. La respuesta final tonalmente satisfactoria en forma de sol mayor, sólo la obtenemos después de muchas fluctuaciones, en el acorde final.

\section{EJEMPLOS MUSICALES}

Definición de la tonalidad. A continuación se muestra un aparte del primer movimiento, cuya tonalidad no se define sino hasta el final con la entrada del sexto grado.

Ilustración 1. Primer movimiento -Compases diez al diecisiete-
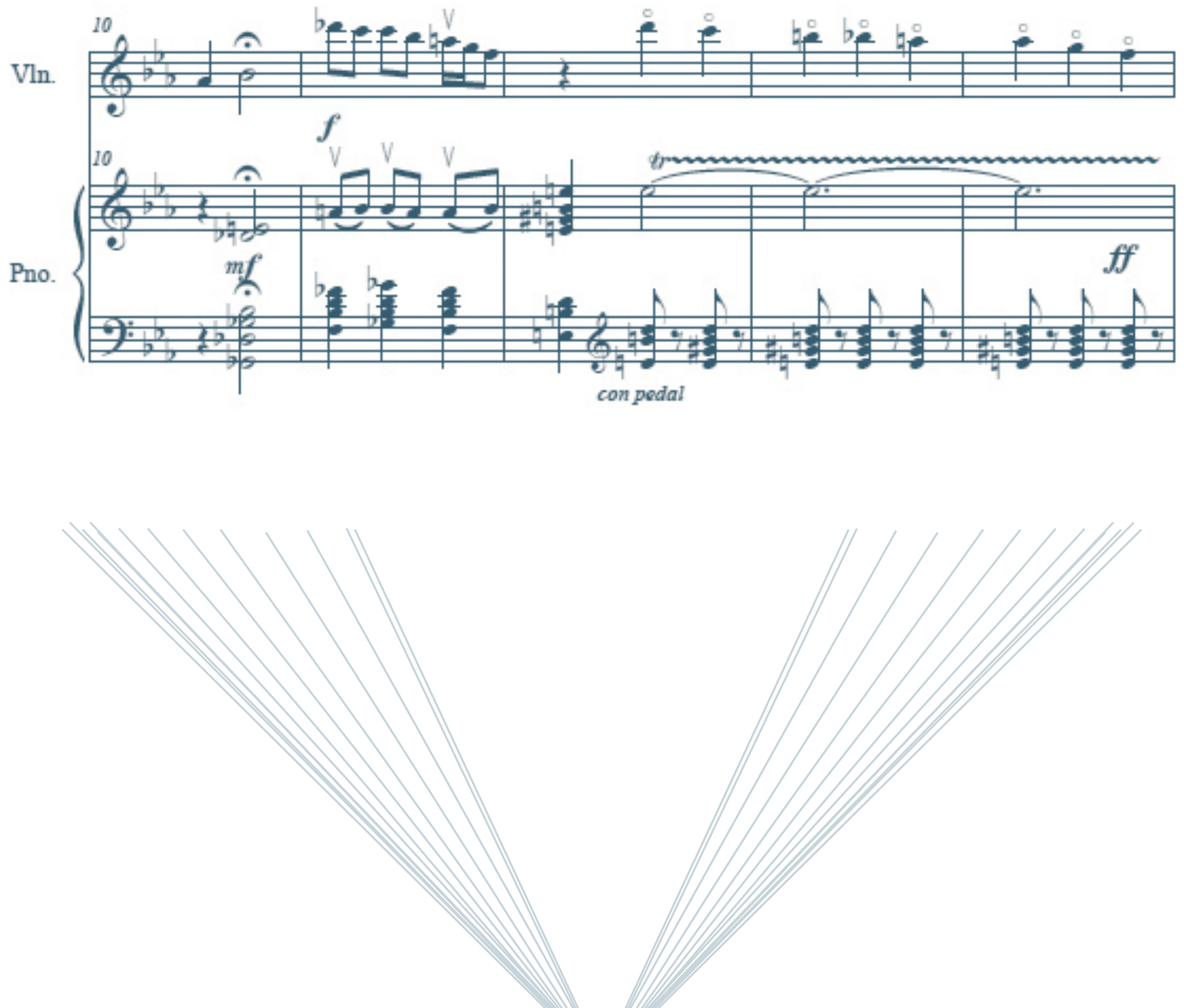


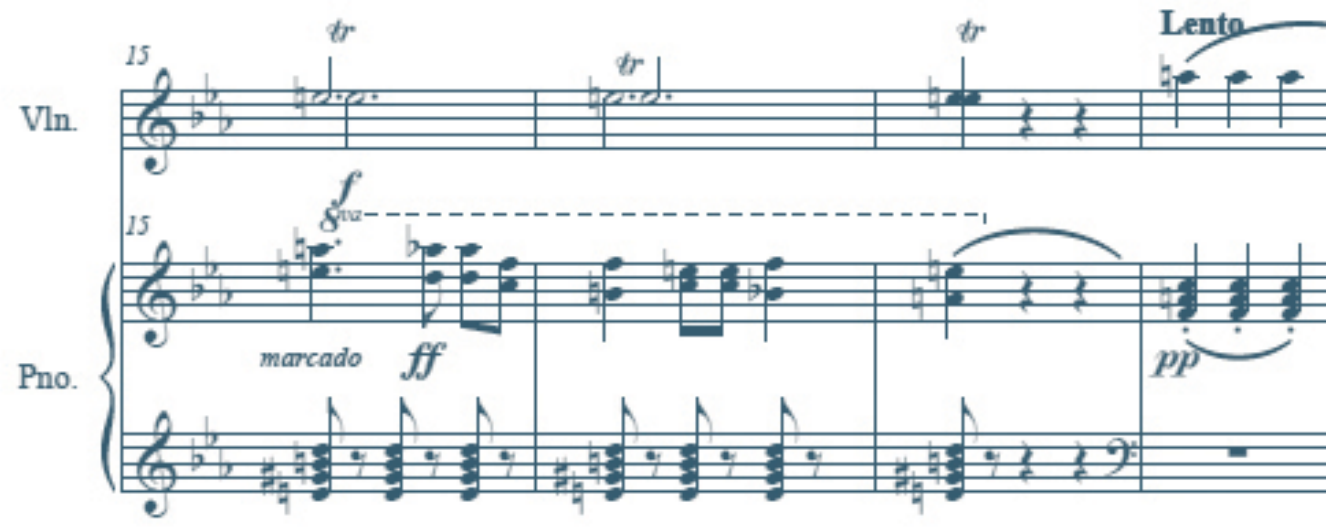

Sonoridad cuartal. La ilustración 2 muestra acordes con sonoridad cuartal.

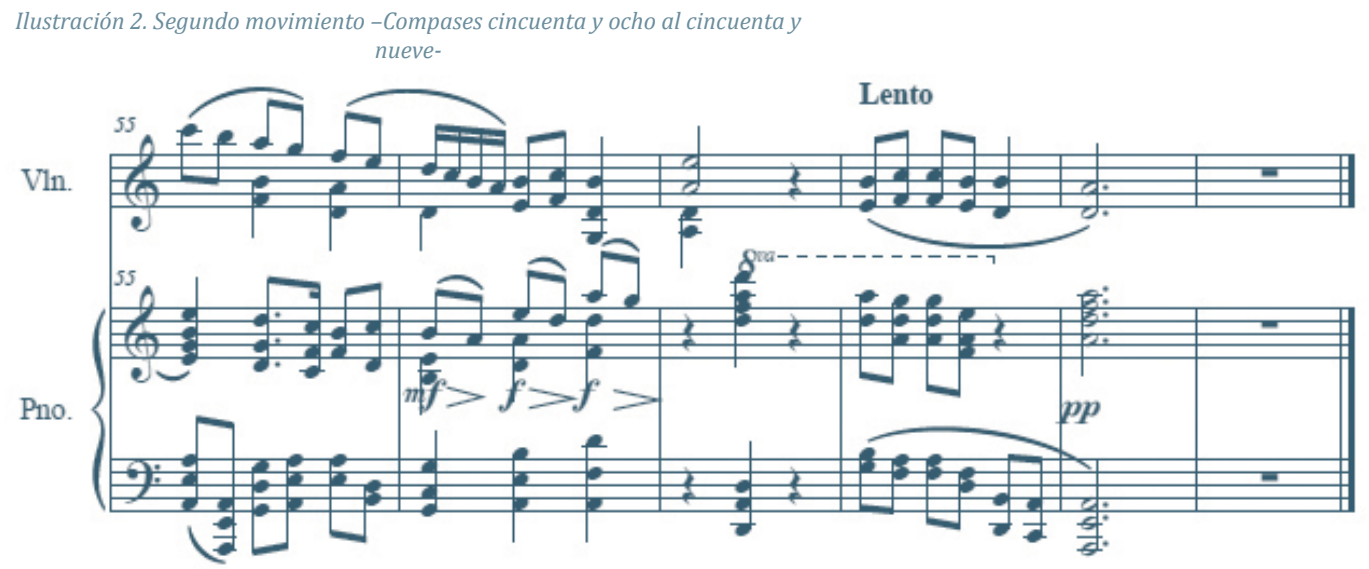

Muestra de falsa relación. El mi bemol de la voz inferior del piano no corresponde con el mi natural del violín. Éste puede ser un error de escritura en el manuscrito de la partitura. Como este ejemplo, se encuentran varios en la sonata. Cabe aclarar que no existe el manuscrito original de la obra; la fuente usada para este trabajo es una copia manuscrita de autor desconocido, por lo cual, las falsas relaciones antes de ser atribuidas al compositor podrían ser entendidas como errores de escritura. 

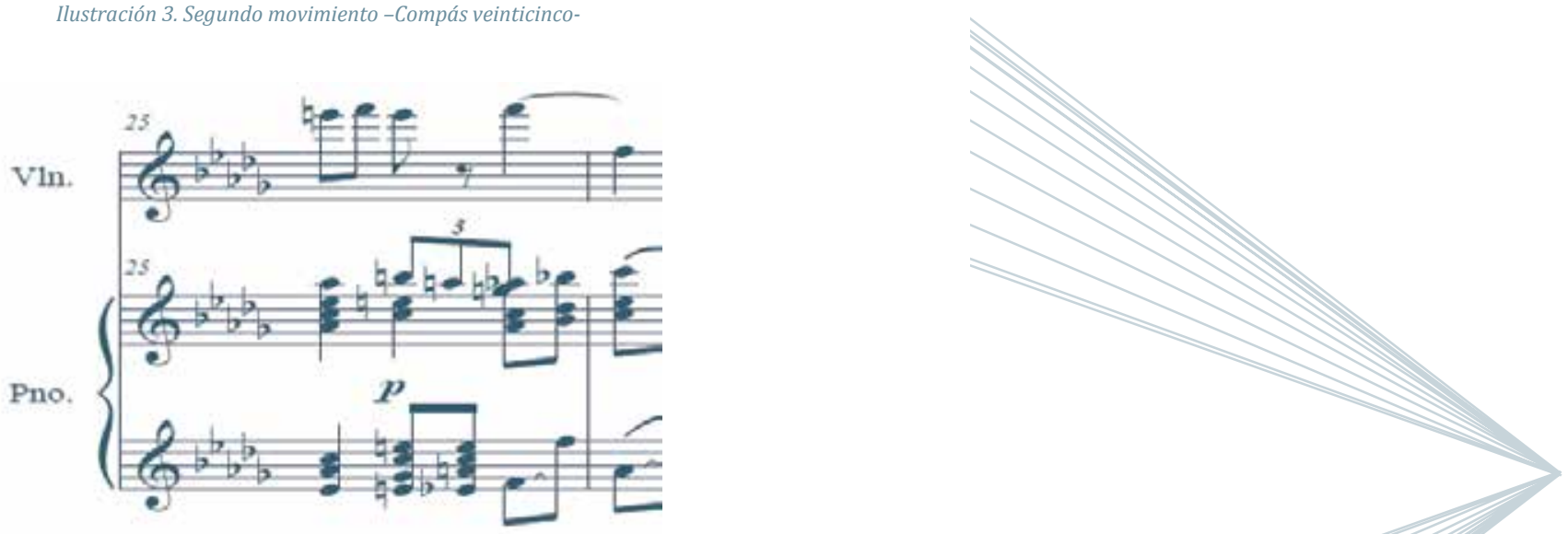

Notas falsas. La disonancia del compás veintitrés en la voz del violín no es consecuente con la idea musical de la pieza. Este punto se discutió especialmente con Amparo Ángel y se acordó omitir la disonancia. Como este ejemplo, hay varios dentro de la obra. (Compás 41 primer movimiento; compás 43 segundo movimiento; compás 56 y 57 tercer movimiento.)

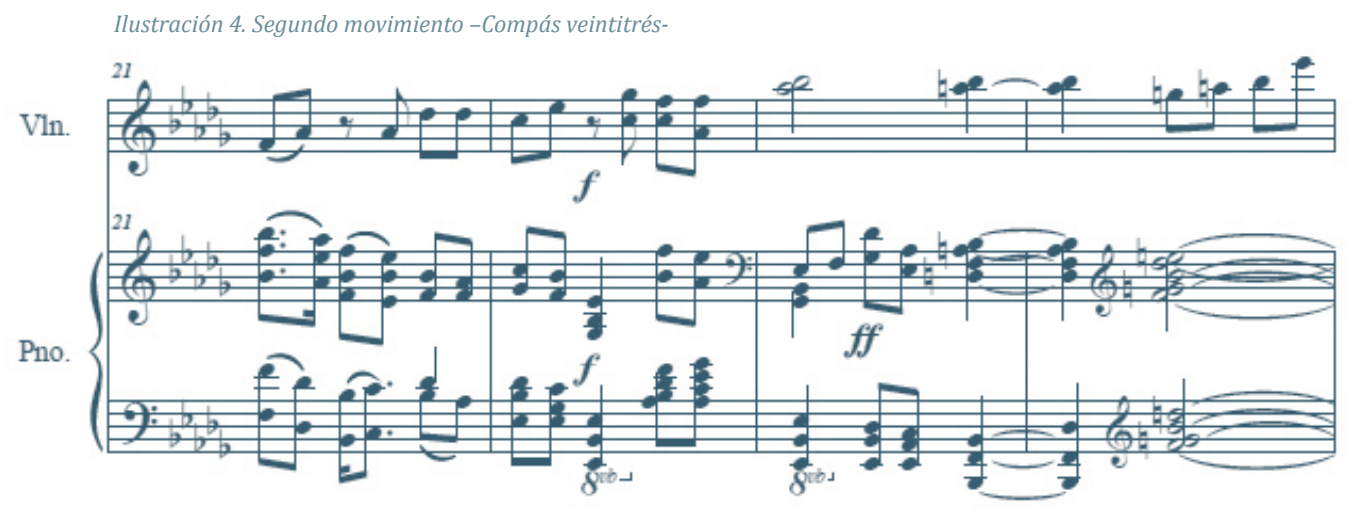

\section{CONLUSIONES}

La temprana carrera de Escobar como compositor encontró eco en la propuesta musical generada por el concurso Música de Colombia de Fabricato. En las décadas de los 40 s y 50 s, se crearon concursos musicales que cultivaron el nacionalismo musical del país y el de Fabricato fue uno de ellos. Este concurso, no sólo impulsó el arte de Escobar, sino que promovió la elaboración de la obra que, como se refleja en el análisis, es digna representante de una identidad nacional y de una época cultural. 
La asociación empresa colectiva y empresa individual son proyectadas hacia el futuro a través de la música en uno de los ejemplos de asociación cultural y empresarial más relevantes en el país. Nuestro deber es dar significado a este esfuerzo, reviviendo una música que testimonia, no sólo la historia de aquella época, sino las bases sobre las que se construiría lo que vendría después.

En este sentido, es preponderante revaluar los procesos culturales que se dan en el país con el ánimo de impulsar mejores decisiones que conduzcan a una difusión de la música académica y a su mejor entendimiento, así como también realzar la labor de nuestros compositores. Nuestro trabajo pone a consideración la primera edición de una sonata compuesta hace más de 50 años y que obtuvo mención de honor. Su primera grabación sonora está incluida en este documento. Y en cuanto al catálogo completo del compositor, sólo este año fue concluido por Amparo Ángel.

Es importante traer a la vida este repertorio de cámara para violín y piano de Escobar, y además, el de muchos otros compositores nacionales, no sólo por su contribución histórica y musical, sino, para crear un espacio en la sociedad que motive nuevamente el flujo de ideas nacionalistas pero ahora dentro del marco de la modernidad.

Sirva este trabajo para impulsar nuestro sentido de apropiación patrimonial, para emprender labores investigativas de nuestra herencia musical, para encontrar nuestro rumbo y características de raza, región y cultura.

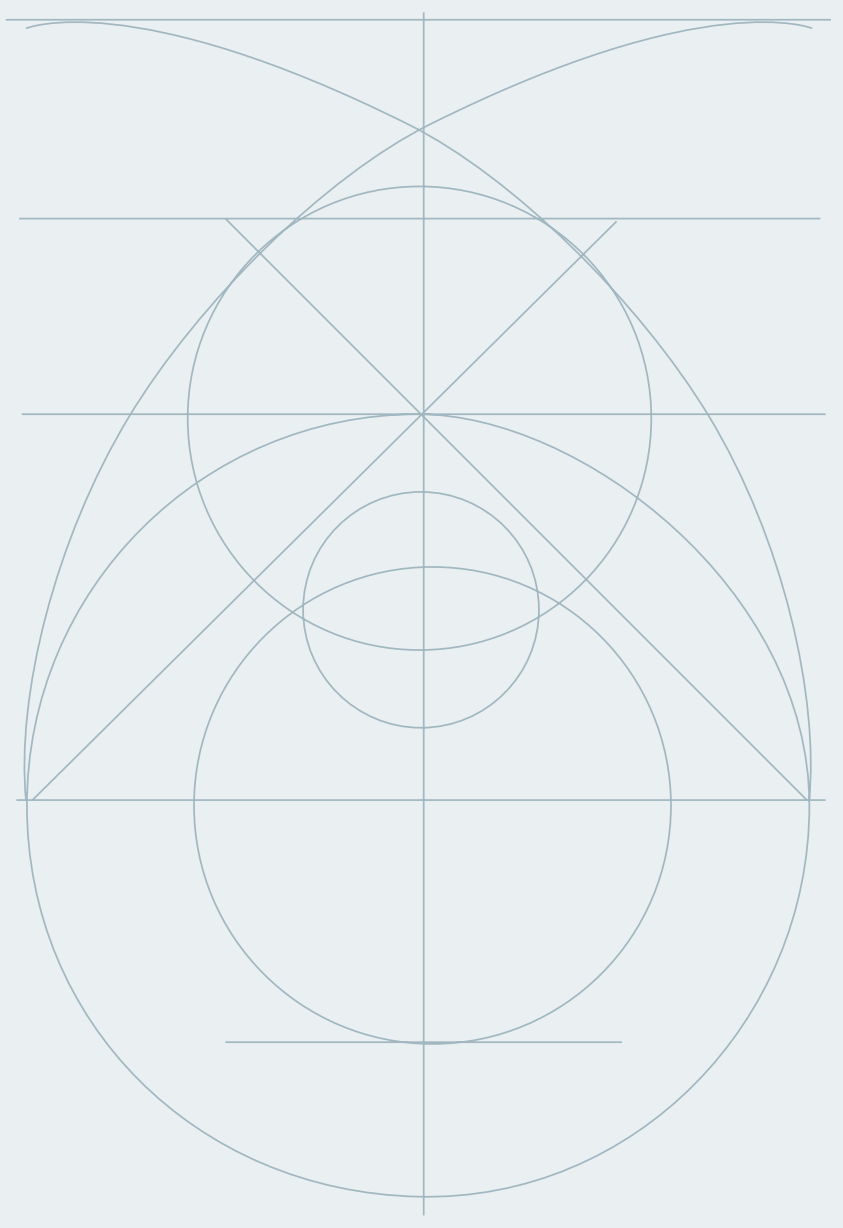




\section{BIBLIOGRAFÍA}

Ángel, A. (2001). Luis Antonio Escobar. Compositor colombiano [En linea]. Bogotá: Biblioteca Virtual del Banco de la Republica. (citada: 22 julio de 2011) http://www.banrepcultural.org/blaavirtual/musica/ blaaaudio/compo/escobar/indice.htm\#1925-1993

Arango Montoya, J. C. (1982). Escobar, Luis Antonio. Hoja de vida y catálogo de sus obras. Bogotá: Josmar Impresores, 26p.

Atehortúa Almanya, W. (2003). Escobar, Luis Antonio [En línea]. Bogotá: Biblioteca Virtual Biblioteca Luis Ángel Arango, 2003. (Citada: 10 Octubre de 2011) http:// banrepcultural.org/blaavirtual/biografias/escoluis.htm

Banco De La República. (2012). Catálogo de obras. Obras para orquesta. [En Línea]. Bogotá: Biblioteca Luis Ángel Arango. (Citada: 7 de septiembre de 2012) http://www.banrepcultural.org/node/66131

Barreiro, C. y Escobar, L. A. (2011) [En línea]. Multimanía. (Citada: 1 septiembre de 2011) http:// usuarios.multimania.es/mincho/biografias/Escoblui.htm

Bermúdez, E. (1999). Un siglo de música en Colombia. ¿Entre Nacionalismo y Universalismo? En: Credencial Historia. Vol. 120. p8-10

Dahlhaus, C. (1972). Rieman Musik Lexikon. Mainz: B. Schott's Söhne. p.330

De Greiff, O. (2006). Escritos sobre música clásica en la Colombia del Siglo XX. Selección. Medellín: Secretaria de educación de antioquia. 393p

Duque, E. A. (1993). La cultura musical en Colombia, siglos XIX y XX. En: Gran Enciclopedia de Colombia. Bogotá: Círculo de lectores, Vol. 6.

Duque, E. A. (1999). Luis Antonio Escobar. Neoclasicismo y nacionalismo gratos de oír. En: Credencial Historia. Diciembre. Vol. 120. 12p.

Escobar, L. A. (1948). Sonata para violín y piano sobre temas colombianos [Partitura]. Medellín: Concurso de Música Fabricato. 18 p.
Escobar, L. A. (2011). Cánticas colombianas. Luis Antonio Escobar. Medellín: Fondo editorial Universidad EAFIT. 68p.

Gil Araque, F. (2003). Ecos, Contextos y Desconciertos. La composición y la práctica musical entorno al concurso Música de Colombia, patrocinado por Fabricato: 1948-1951. Alcances y Aportes. Medellín: Universidad EAFIT. 271p

Gil Araque, F. (2006). Temas con Variaciones. Medellín a través de su música 1900-1960. Medellín: Universidad EAFIT.

Jacobs, A. (1995). Diccionario de Música. Buenos Aires: Editorial Losada. 511p

López Calo, J. (1999). Diccionario de la música española e hispanoamericana. Barcelona: Sociedad general de autores y editores, Vol. 4.953p

Perdomo Escobar, J. I. (1980). Historia de la Música en Colombia. Bogotá: Plaza y Janés. 293p

Posada, A. (2004). La proyección de la nueva música en América Latina. Globalización y periferia [En linea]. Colegio de Compositores Latinoamericanos de música de arte. http://www.colegiocompositores-la.org/ articulo.asp?id=61

Sadie. 1980. The new grove dictionary of music and musicians. Londres: Macmillan. 1980, Vol. 2, p. 766, Vol. 6, p. 243, Vol. 13, p 10

Sierra, A. (1948). Acta Jurado Calificador. En: Revista Gloria. Medellín: Fabricato 13, 68p.

Slonimsky, N. (1984). Baker's biographical dictionary of musicians. New York: Macmillan, 2115p.

Universidad EAFIT - Biblioteca Luis Echavarría Villlegas (2006). Biblioteca digital de música [En línea]: página Web. Medellín: La Biblioteca. (Citada: 2 Octubre de 2011) http://www.bdmusica.eafit.edu.co/partituras 

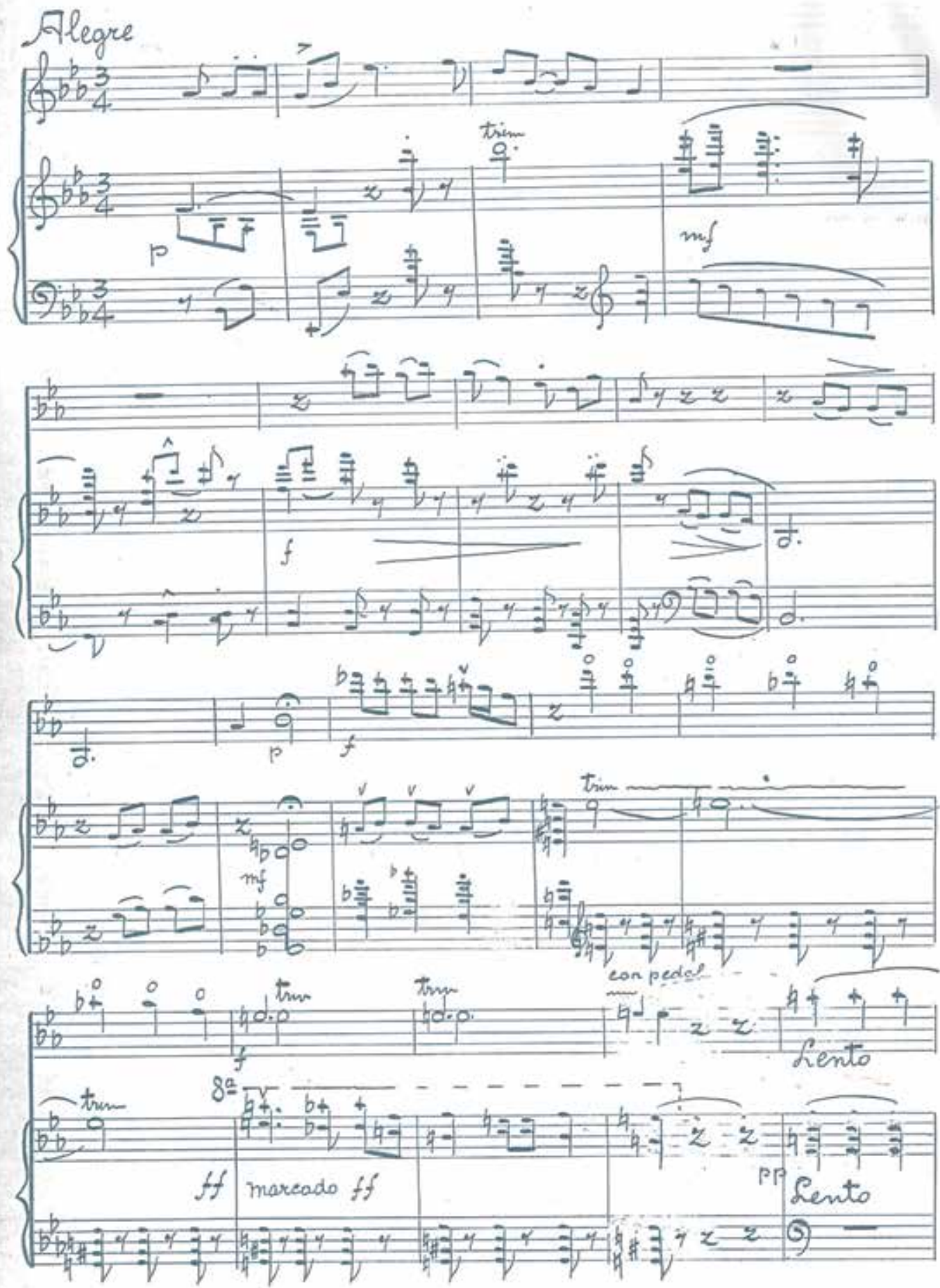

Dorma 